OPEN ACCESS

Edited by:

Julio Alvarez,

University of Minnesota, USA

Reviewed by:

Lorenzo Fraile,

University of Lleida, Spain

Hsin-yi Weng,

Purdue University, USA

*Correspondence:

loannis Magouras

ioannis.magouras@vetsuisse.

unibe.ch

Specialty section: This article was submitted to Veterinary Epidemiology and

Economics,

a section of the journal Frontiers in Veterinary Science

Received: 23 November 2016 Accepted: 14 February 2017 Published: 02 March 2017

Citation:

Carmo LP, Nielsen LR, Alban L, Müntener CR, Schüpbach-Regula $G$ and Magouras I (2017) Comparison of Antimicrobial Consumption

Patterns in the Swiss and Danish Cattle and Swine Production (2007-2013).

Front. Vet. Sci. 4:26 doi: 10.3389/fvets.2017.00026

\section{Comparison of Antimicrobial Consumption Patterns in the Swiss and Danish Cattle and Swine Production (2007-2013)}

\author{
Luís P. Carmo', Liza R. Nielsen², Lis Alban ${ }^{3}$, Cedric R. Müntener', \\ Gertraud Schüpbach-Regula ${ }^{1}$ and loannis Magouras ${ }^{1 *}$
}

\begin{abstract}
${ }^{1}$ Vetsuisse, Veterinary Public Health Institute, University of Bern, Bern, Switzerland, ${ }^{2}$ Faculty of Health and Medical Sciences, Department of Veterinary and Animal Sciences, University of Copenhagen, Copenhagen, Denmark, ${ }^{3}$ Danish Agriculture \& Food Council, Copenhagen, Denmark, ${ }^{4}$ Institut für Veterinärpharmakologie und -toxikologie, Vetsuisse, University of Zurich, Zurich, Switzerland
\end{abstract}

Veterinary antimicrobial consumption patterns vary considerably across Europe. These differences are not only limited to the total amount consumed but are also observed with regards to the relative proportion of the various antimicrobial classes used. Currently, most of the data on veterinary antimicrobials are reported at sales level without any information on the consumption by different animal species. This hinders a proper comparison of antimicrobial consumption at the species level between countries. However, it is imperative to improve our understanding on antimicrobial usage patterns at the species level, as well as on the drivers contributing to those differences. This will allow for development of tailored interventions with the lowest possible risk for human health, while ensuring effective treatment of diseased livestock. An important step to attain such an objective is to perform detailed comparisons of the antimicrobial consumption in each species between countries. We compared antimicrobial consumption estimates for cattle and pigs in Switzerland and Denmark, in order to distinguish species-specific patterns and trends in consumption from 2007 to 2013. Swiss data were obtained from a previous study that assessed methodologies to stratify antimicrobial sales per species; Danish antimicrobial consumption estimates were assembled from Danish Integrated Antimicrobial Resistance Monitoring and Research Programme reports. A decrease in antimicrobial consumption in milligrams per kilogram of biomass was observed for both countries (4.5\% in Denmark and 34.7\% in Switzerland) when comparing 2013 to 2007. For pigs and cattle, the overall consumption per kilogram of biomass of most antimicrobial classes was higher in Switzerland than in Denmark. Large variations in the relative consumption of different antimicrobial classes were also evident. Sulfonamides/ trimethoprim and tetracyclines were consumed in a higher proportion in Switzerland than in Denmark, whereas the relative consumption of penicillins was higher in Denmark. The differences observed in veterinary antimicrobial consumption are not solely related to animal demographic characteristics in these two countries. Other factors, such as the level of biosecurity and farming practices, veterinarians and farmers' education, or 
governmental/industry programs put in place might also partly explain these variations. These differences should be taken into account when aiming to implement targeted interventions to reduce antimicrobial consumption.

Keywords: antimicrobial consumption, antibiotics, antimicrobial resistance, Switzerland, Denmark, pigs, cattle

\section{INTRODUCTION}

Considerable differences in veterinary antimicrobial sales have been observed across European countries. This heterogeneity is not only evident in the total amounts but also in the proportions of the different antimicrobial classes sold (1-5).

A variety of factors might be related to the abovementioned variations: infection status (at farm and country level), animal husbandry practices and general animal keeping conditions, onfarm biosecurity and targeted disease control programs, prescription practices, product availability and price, veterinarians' and farmers' preferences over specific products, as well as farmers' and veterinarians' education and habits (6-9).

The reports from the European Surveillance on Antimicrobial Consumption (ESVAC) project provide an initial basis for comparing antimicrobial sales between European countries (1-5). However, they do not include data on consumption at the species level, but only sales data normalized to biomass of foodproducing animals. When assessing overall sales data, it should be noted that animal demographics are heterogeneous among European countries. This could partly explain some of the variations observed in the total antimicrobial sales (6). Furthermore, the level of antimicrobial exposure for individual animals varies greatly between production sectors (10). With that in mind, more meaningful comparisons can be achieved by analyzing antimicrobial use at species level. In addition, overall sales do not allow the implementation of benchmarking strategies, thus targeted approaches to reduce antimicrobial consumption are not feasible.

Nonetheless, only few countries collect data at the species level. In Switzerland, sales data have been collected from marketing authorization holders since 2004 (11). No national data are available at farm level, but a methodology has recently been developed to attribute sales data to animal species (12). Denmark has recorded antimicrobial prescription data since 2001 in the VetStat database (13). The comparison between these two countries is of particular interest as, despite similar animal health status, Switzerland is characterized by a higher antimicrobial consumption in livestock per kilogram of animal biomass compared to Denmark (5). This indicates that additional factors, beyond the animal health status, might drive antimicrobial consumption in both countries. A first step to a profound understanding of these differences is to investigate which species and antimicrobial class combinations differ most between the two countries. Benchmarking antimicrobial consumption (at the species level) between countries can improve the value of these data sources and can lead to more tailored and effective reduction measures. If differences in the overall and relative consumption of different antimicrobial classes exist at the species level, there is a need to highlight them and study potential underlying factors, in order to develop more specific interventions. In addition, the successful implementation of interventions in one country could provide evidence-based motivation for other countries to follow their paradigm.

We analyzed available antimicrobial consumption data from Denmark and Switzerland with the following objectives: (a) to compare the patterns and trends of antimicrobial consumption in cattle and pigs and (b) to compare the relative consumption of different antimicrobial classes in the different species and countries.

\section{MATERIALS AND METHODS}

\section{Antimicrobial Consumption Estimates in Switzerland}

In a previous study, Swiss sales of all veterinary antimicrobials products were stratified by animal species (12). Consumption estimates for cattle and pigs referred to in the present study were derived from the model entitled "Longitudinal Study Extrapolation" (LSE). In the LSE approach, sales data were combined with information from a field study by Regula et al. (14), where prescription patterns of 8 veterinary practices (with a total of 15 veterinarians) were investigated. The veterinary clinics enrolled in the study were selected based on the proportion of owners keeping livestock and the availability of electronic databases for disease and prescription records; they represented $1.5 \%$ of all large and mixed veterinary clinics in Switzerland. The animal species included in this study were cattle, pigs, sheep, goats, horses, dogs, and cats (14). To take uncertainty into account, Pert distributions were used in Monte Carlo simulation models to estimate the total amount of antimicrobials consumed by each animal species in a year and at antimicrobial class level. Prescription practices from the study by Regula et al. (14) were used to estimate the mode of the Pert distributions. Minimum and maximum were calculated using official sales data by the Swiss Federal Food Safety and Veterinary Office by taking into account which products were licensed for each species.

These results represent a proxy of antimicrobial consumption. To improve readability of the manuscript, estimated consumption will be referred to hereafter as "consumption."

\section{Antimicrobial Consumption Estimates in Denmark}

Denmark developed an electronic database (VetStat) to collect veterinary prescription information in 2001 (13). Data from all antimicrobial prescriptions at species level are published annually in the reports from The Danish Integrated Antimicrobial 
Resistance Monitoring and Research Programme (DANMAP). Data on cattle and pig's consumption (2007-2013) of different antimicrobial classes were collated from the DANMAP reports (15-21).

Between 2007 and 2009, antimicrobial consumption data were reported in DANMAP as prescriptions made directly to the farmers and antimicrobials sold for use in veterinary practice. For this time period, these values were added up to estimate the total antimicrobial consumption for each species. From 2009 onward, prescriptions made directly to the farmers and antimicrobials sold for use in veterinary practice were already summed up when presented in DANMAP reports.

\section{Animal Demographic Data}

The national total biomass was calculated for each animal species according to the population correction unit (PCU) method (1). Average animal weights followed the ESVAC recommendations. Animal population data for each study year were obtained from ESVAC reports (1-5). Cattle data included all production bovines in the countries-dairy and beef cattle. It should be noted that dairy and non-dairy proportions varied between the two countries $(22,23)$.

\section{Comparison between the Two Countries}

Antimicrobial consumption was calculated in milligrams per kilogram biomass (mg/BM) annually from 2007 to 2013. This metric differs from milligrams per PCU solely by the fact that the latter was coined to specifically account for the biomass of multiple animal species in the denominator, while $\mathrm{mg} / \mathrm{BM}$ can be calculated for specific animal species.

Unless stated otherwise, differences on antimicrobial consumption over the study period were calculated by subtracting the antimicrobial consumption in $\mathrm{mg} / \mathrm{BM}$ (or corresponding percentage) in 2013 and 2007.

Specific antimicrobial class consumption estimates were also calculated for each species and country. The relative consumption of each antimicrobial class in each country was calculated as

$$
\begin{aligned}
& \text { Relative consumption } \text { antimicrobial class, species, year } \\
& \qquad=\frac{\mathrm{mg} / \mathrm{BM}_{\text {antimicrobial class, species, year }}}{\mathrm{mg} / \mathrm{BM}_{\text {species, year }}} \times 100
\end{aligned}
$$

\section{Data Analysis}

Data management and descriptive analyses were performed in MS Excel (24). A correlation analysis between years and antimicrobial consumption was performed for each combination of species/antimicrobial class/country. The Pearson correlation coefficient was used as measure. This analysis was done using the statistical software $\mathrm{R}$ version 3.1.0.

\section{RESULTS}

\section{Antimicrobial Consumption Estimates in Cattle}

Calculated antimicrobial consumption in the Swiss cattle population was more than twice as high as observed in Denmark. In Switzerland, a $24.5 \%$ reduction was observed from a maximum of 89.3 [51.3-113.2] $\mathrm{mg} / \mathrm{BM}$ in 2008 to 67.4 [38.7-85.4] $\mathrm{mg} / \mathrm{BM}$ in 2013. In Denmark, antimicrobial consumption in cattle was lower and varied over the study period between a maximum of $37.6 \mathrm{mg} / \mathrm{BM}$ in 2009 and a minimum of $29.8 \mathrm{mg} / \mathrm{BM}$ in 2013, which corresponds to a reduction of $20.8 \%$ (Figure 1).

\section{Antimicrobial Consumption Estimates in Pigs}

Antimicrobial consumption for pigs in Switzerland was also higher than in Denmark. However, when compared to cattle, a steeper decrease $(31.5 \%)$ of antimicrobial consumption was observed in Switzerland for pigs, from a maximum of 110.9 [54.0-201.3] mg/BM in 2007 to a minimum of 75.9 [34.0-143.8] $\mathrm{mg} / \mathrm{BM}$ in 2013. In Denmark, there was a decrease of $1.9 \%$ in the consumption of antimicrobials for pigs, when comparing 2013 to 2007. It should, however, be noted that a marked reduction was achieved from 2009 (57.0 mg/BM) to 2011 (44.4 mg/BM). After this decrease, antimicrobial consumption increased again to $51.0 \mathrm{mg} / \mathrm{BM}$ in 2013 (Figure 2).

\section{Antimicrobial Classes' Consumption Estimates for Cattle}

The estimated antimicrobial consumption for Swiss cattle was higher for every antimicrobial class when compared to Danish cattle; except for penicillins from 2008 onward, where a lower consumption was observed for Swiss than for Danish cattle. The largest absolute differences were observed for sulfonamides/ trimethoprim and tetracyclines (Table 1).

Variations in the relative consumption of antimicrobial classes within each country are presented in Figures $\mathbf{3 A}, \mathbf{B}$. In Switzerland, sulfonamides (in combination with trimethoprim) were the antimicrobial class sold the most for cattle (between $49.8 \%$ [27.2-63.2\%] of the overall $\mathrm{mg} / \mathrm{BM}$ in 2007 and $40.8 \%$ [22.2-52.0\%] in 2013). Simultaneously, an increase in the relative consumption of penicillins was observed. In Denmark, penicillins were the antimicrobial class with the largest consumption (between 53.3\% of the total mg/BM in 2007 and 66.2\% in 2013).

Important differences between the two countries were observed regarding the relative consumption of antimicrobial classes for cattle. Sulfonamides/trimethoprim, tetracyclines, macrolides, as well as cephalosporins and fluoroquinolones, had a higher relative consumption in Switzerland than in Denmark. The values for aminoglycosides were similar-between $7.0 \%$ (2007) and 4.4\% (2013) for Denmark; and 4.4\% [2.5-5.8\%] (2010) and 5.1\% [3.0-6.7\%] (2013) for Switzerland. The relative consumption of penicillins in Denmark was on average $37.7 \%$ larger than in Switzerland (Table 1).

\section{Antimicrobial Classes' Consumption Estimates for Pigs}

Throughout the study period, the relative consumption of penicillins in swine was higher in Denmark than in Switzerland (15.9\% on average-Table 2). The relative consumption of macrolides was similar for both countries. With the exception of aminoglycosides in 2007, consumption in Switzerland was higher for all other classes. 


\section{Antimicrobial consumption ( $\mathrm{mg}$ per $\mathrm{kg}$ of biomass) in cattle from 2007 to 2013}

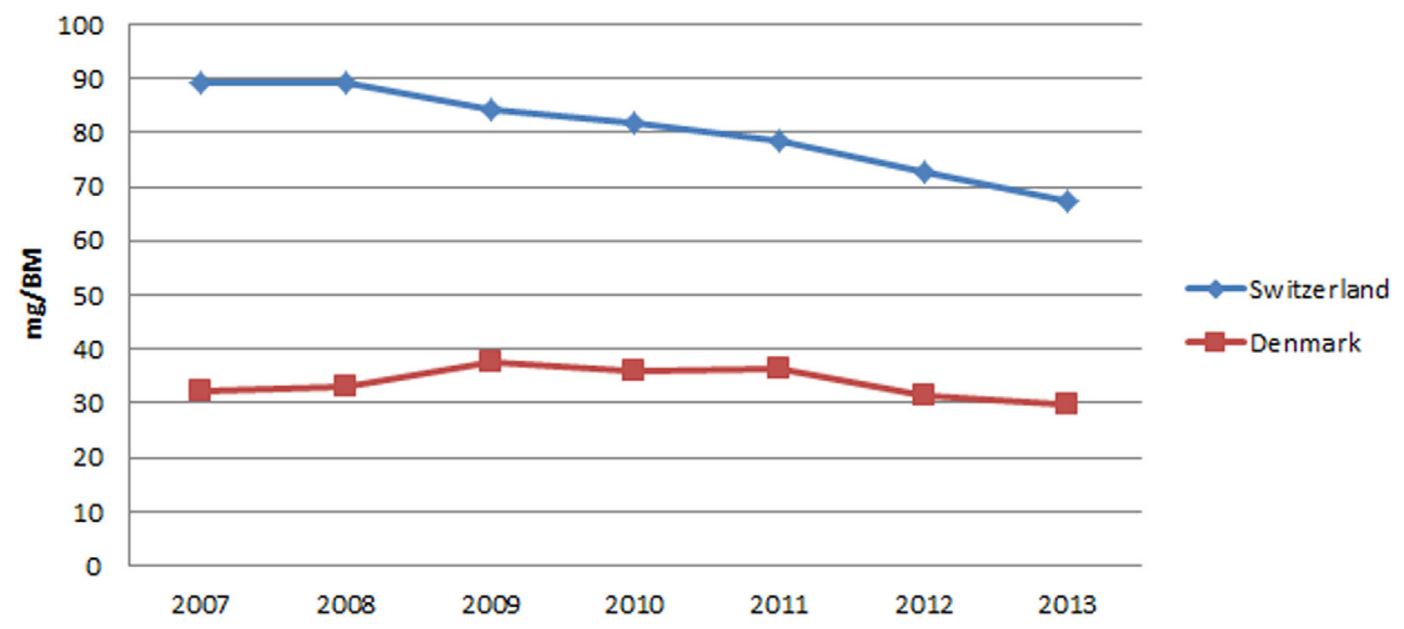

FIGURE 1 | Temporal patterns in antimicrobial consumption for cattle in Denmark and Switzerland from 2007 to 2013

\section{Antimicrobial consumption (mg per kg of biomass) in pigs from 2007 to 2013}

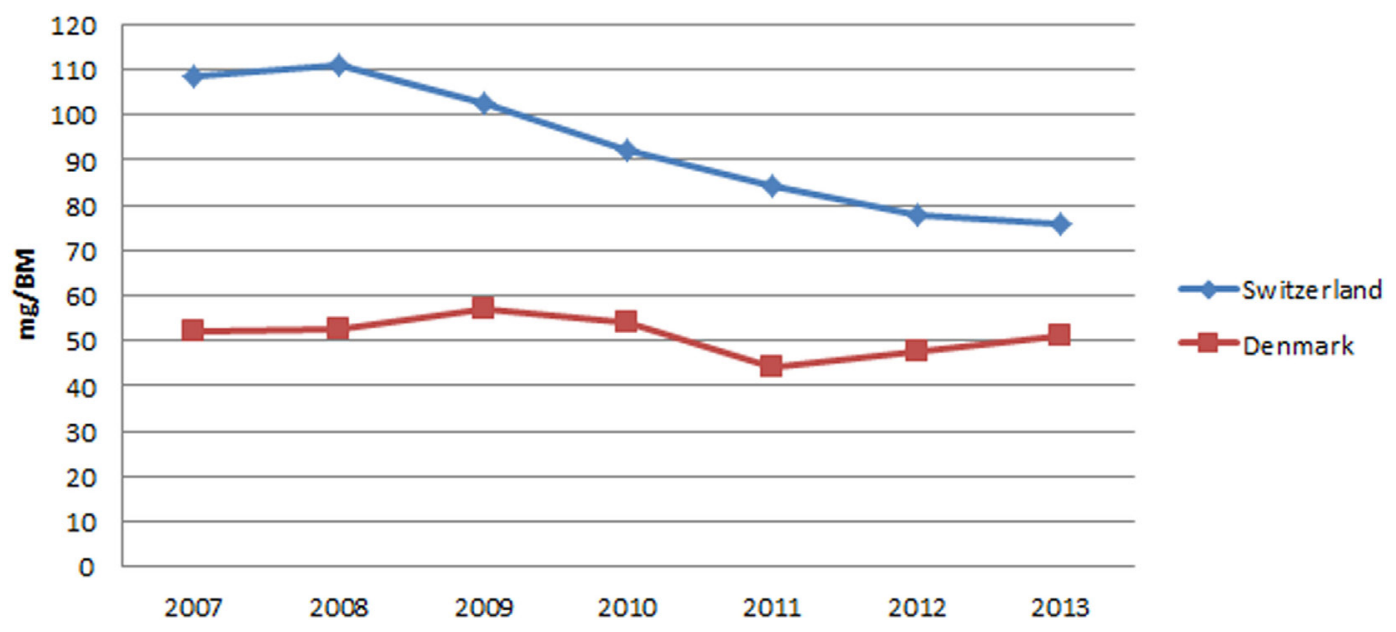

FIGURE 2 | Temporal patterns in antimicrobial consumption for pigs in Denmark and Switzerland from 2007 to 2013

As observed for cattle, the differences in antimicrobial consumption between the two countries were especially pronounced for sulfonamides/trimethoprim and tetracyclines (Table 2).

In line with what was observed for cattle, within-country variation in the relative consumption of antimicrobial classes throughout the years was not large (Figures 4A,B). In Switzerland, there was a decrease in the relative consumption of tetracyclines, from a maximum of $37.2 \%$ [28.8-51.8\%] of the total $\mathrm{mg} / \mathrm{BM}$ in 2008 to a minimum of $28.8 \%$ [18.1-47.2\%] in 2012. At the same time, there was an increase in the relative consumption of penicillins and macrolides. In Denmark, the proportion of antimicrobial classes used was rather stable, with only few fluctuations.

We observed clear differences between the two countries with respect to the relative consumption of antimicrobial classes for pigs. Sulfonamides/trimethoprim had a lower relative consumption in Denmark (between $7.5 \%$ of the total $\mathrm{mg} / \mathrm{BM}$ in 2008 and $9.8 \%$ in 2013) when compared with Switzerland (minimum of $37.4 \%$ [14.1-76.6\%] in 2013 and a maximum of $40.2 \%$ [15.4-83.2\%] in 2012). On the other hand, macrolides and 
TABLE 1 | Calculated antimicrobial consumption (in milligrams per kilogram biomass) of different antimicrobial classes for cattle in Denmark and Switzerland (2007-2013).

\begin{tabular}{|c|c|c|c|c|c|c|c|c|c|}
\hline $\begin{array}{l}\text { Antimicrobial } \\
\text { class }\end{array}$ & Country & 2007 & 2008 & 2009 & 2010 & 2011 & 2012 & 2013 & $\begin{array}{c}\text { Average percentage } \\
\text { of consumption per } \\
\text { country }\end{array}$ \\
\hline \multirow[t]{3}{*}{ Aminoglycosides } & Denmark & 2.3 & 2.0 & 2.2 & 2.0 & 1.9 & 1.6 & 1.3 & 5.6 \\
\hline & Switzerland & 4.3 & 4.1 & 3.8 & 3.6 & 3.7 & 3.6 & 3.4 & 4.7 \\
\hline & & [2.5-5.6] & {$[2.4-5.4]$} & [2.3-5.2] & {$[2.1-4.7]$} & {$[2.1-4.9]$} & {$[2.1-4.7]$} & [2.0-4.6] & [2.8-6.2] \\
\hline \multirow{3}{*}{$\begin{array}{l}\text { Cephalosporins and } \\
\text { fluoroquinolones }\end{array}$} & Denmark & 0.2 & 0.3 & 0.2 & 0.3 & 0.3 & 0.3 & 0.3 & 0.8 \\
\hline & Switzerland & 0.8 & 0.9 & 1.0 & 1.0 & 1.0 & 0.9 & 1.0 & 1.1 \\
\hline & & {$[0.6-1.0]$} & {$[0.6-1.1]$} & {$[0.7-1.1]$} & {$[0.8-1.2]$} & {$[0.7-1.1]$} & [0.7-1.0] & {$[0.7-1.1]$} & [0.9-1.3] \\
\hline \multirow[t]{3}{*}{ Macrolides } & Denmark & 1.1 & 0.8 & 0.8 & 0.5 & 0.6 & 0.5 & 0.5 & 2.0 \\
\hline & Switzerland & 5.1 & 5.3 & 4.9 & 4.5 & 4.4 & 4.0 & 3.8 & 5.7 \\
\hline & & {$[2.3-7.2]$} & {$[2.4-7.6]$} & [2.2-6.9] & {$[2.0-6.4]$} & [2.0-6.2] & {$[1.9-5.7]$} & {$[1.7-5.3]$} & [2.6-8.0] \\
\hline \multirow[t]{3}{*}{ Penicillins } & Denmark & 17.1 & 19.1 & 22.1 & 22.3 & 22.7 & 20.3 & 19.7 & 60.7 \\
\hline & Switzerland & 18.4 & 19.0 & 17.8 & 18.6 & 19.0 & 18.5 & 18.2 & 23.0 \\
\hline & & [12.8-22.3] & [13.0-22.9] & [12.1-21.6] & [12.4-22.8] & [12.7-23.5] & [12.5-22.6] & [12.0-22.2] & [15.5-28.0] \\
\hline \multirow{3}{*}{$\begin{array}{l}\text { Sulfonamides/ } \\
\text { trimethoprim }\end{array}$} & Denmark & 6.0 & 5.5 & 5.9 & 5.0 & 5.2 & 3.4 & 2.7 & 14.3 \\
\hline & Switzerland & 44.5 & 42.3 & 39.8 & 37.6 & 34.3 & 31.4 & 27.5 & 45.7 \\
\hline & & [24.3-56.4] & [22.9-54.2] & [21.6-51.0] & [19.7-48.6] & [18.3-44.9] & [17.1-40.0] & [15.0-35.1] & [24.7-58.6] \\
\hline \multirow[t]{3}{*}{ Tetracyclines } & Denmark & 4.6 & 4.6 & 5.3 & 4.5 & 4.5 & 4.1 & 4.0 & 13.4 \\
\hline & Switzerland & 16.1 & 17.5 & 16.7 & 16.3 & 15.8 & 14.3 & 13.3 & 19.5 \\
\hline & & [8.7-20.5] & [9.5-22.0] & [9.0-21.0] & [8.9-20.6] & [8.7-20.0] & [7.8-18.1] & [7.1-16.8] & [10.6-24.7] \\
\hline \multirow[t]{3}{*}{ Others } & Denmark & 0.9 & 0.9 & 1.1 & 1.1 & 1.4 & 1.3 & 1.3 & 3.3 \\
\hline & Switzerland & 0.2 & 0.2 & 0.2 & 0.2 & 0.2 & 0.2 & 0.2 & 0.3 \\
\hline & & {$[0.1-0.3]$} & {$[0.1-0.4]$} & {$[0.1-0.4]$} & {$[0.2-0.4]$} & {$[0.2-0.4]$} & {$[0.2-0.4]$} & {$[0.2-0.4]$} & {$[0.2-0.5]$} \\
\hline \multirow[t]{3}{*}{ Total } & Denmark & 32.0 & 33.1 & 37.6 & 35.8 & 36.5 & 31.4 & 29.8 & 100.0 \\
\hline & Switzerland & 89.3 & 89.3 & 84.2 & 81.9 & 78.4 & 72.9 & 67.4 & 100.0 \\
\hline & & [51.3-113.2] & {$[50.8-113.7]$} & [48.0-107.2] & {$[46.0-104.7]$} & [44.7-101.0] & [42.2-92.4] & [38.7-85.4] & \\
\hline
\end{tabular}

For Swiss estimates, the 95\% credibility intervals are presented in square brackets. "Others" include amphenicoles, quinolones, lincosamides (combined or not with spectinomycin), pleuromutilins, and polypeptide antibiotics. Due to confidentiality reasons, fluoroquinolones and cephalosporins have been grouped together.

penicillins had a relatively higher consumption in Denmark than in Switzerland.

\section{Correlation Analysis}

A correlation analysis was performed to assess the relationship between antimicrobial consumption and the years included in the study period. The majority of combinations of species/country/ antimicrobial class presented a negative correlation coefficient (Table 3). The closer the correlation coefficients are to -1 or 1 , the strongest the negative or positive, respectively, linear association between the years and antimicrobial consumption.

\section{DISCUSSION}

The antimicrobial consumption in cattle and pigs varied considerably between Denmark and Switzerland in the considered study period (2007-2013). Furthermore, marked differences were found between the countries regarding each species' relative consumption of different antimicrobial classes.

\section{Comparison with Other Studies}

Differences in the use of antimicrobials in different animal species have already been described. Sjölund et al. found variations in the relative usage of different antimicrobial classes in farrow-tofinish pig herds from four European countries (25). Moreover, a comparative study on antimicrobial exposure between Denmark and The Netherlands detected differences in the consumption patterns of several substances in terms of routes of administration, relative consumption of antimicrobial classes, and antimicrobial consumption in different age classes (26).

Even though the amount of marketed active substance is not an ideal measure of usage, the larger amount used in Switzerland compared to Denmark very likely reflects a true difference in usage practice, both in quantities and patterns of use. These findings are in line with the general trend described in the ESVAC reports (1-5) for the same period. Nordic countries (Denmark included) are well known for their conservative use of antimicrobials and many years of activities in place to reduce antimicrobial consumption (18,27-29). While Denmark is one of the countries participating in the ESVAC project with a lower amount of antimicrobials sold per kilogram of animal biomass, Switzerland is in the average (1-5).

\section{Consumption Patterns and Potential Contributing Factors}

It should be stressed that this study was not conducted to assess the factors behind the observed differences between the countries, but rather to compare (at the species level) the antimicrobial consumption patterns in Denmark and Switzerland. Future investigations should provide a formal evaluation of these discrepancies. 


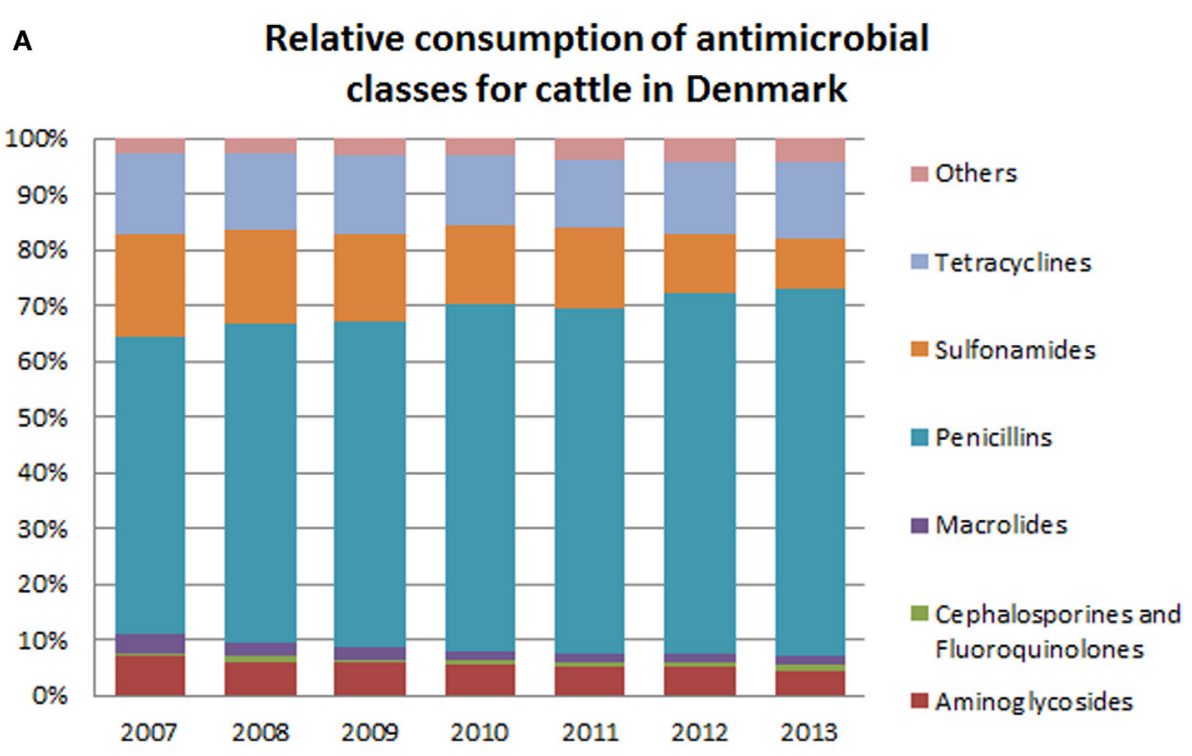

\section{B Relative consumption of antimicrobial classes for cattle in Switzerland}

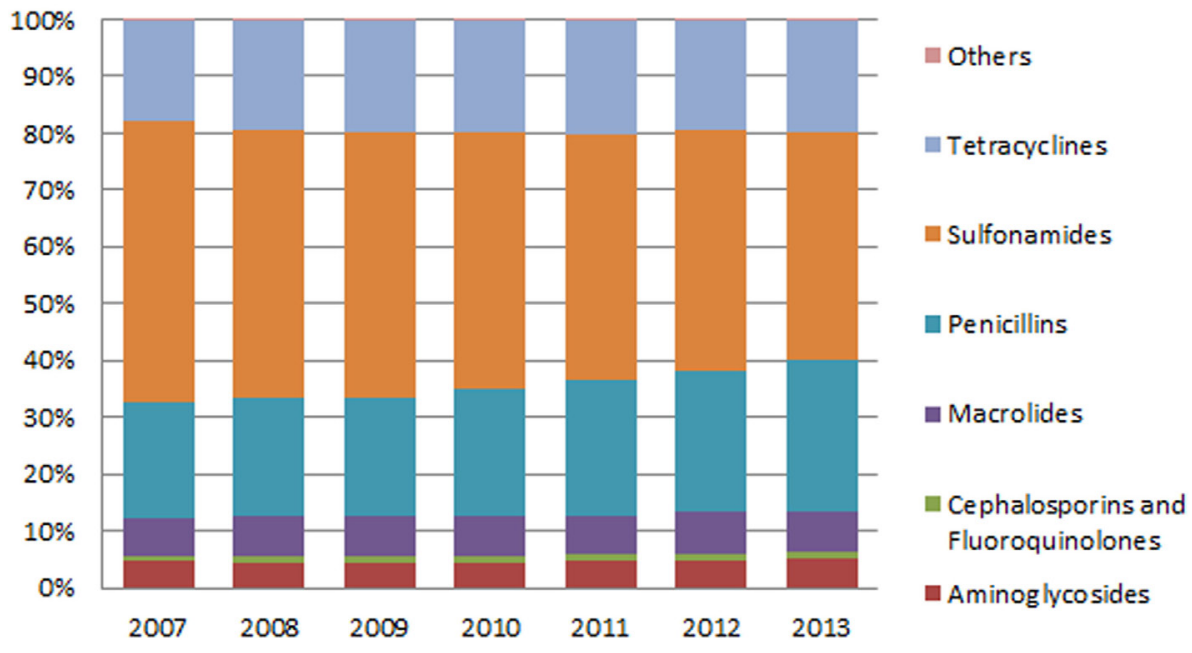

FIGURE 3 | Comparison of the relative consumption of different antimicrobial classes between Denmark (A) and Switzerland (B) for use in cattle. "Others" include amphenicols, quinolone, lincosamide (with or not combination with spectinomycin), pleuromutilins, and polypeptide antibiotics. Due to confidentiality reasons, fluoroquinolones and cephalosporins have been grouped together.

In this section, potential contributing factors are discussed based on the existing literature and on the authors' knowledge about the veterinary practices and the animal production situation in the countries.

Both countries considered in this study presented a decrease in antimicrobial consumption (measured in $\mathrm{mg} / \mathrm{BM}$ ) for cattle and pigs when comparing 2013 to 2007 . This is also attested by the fact that the majority of species/country/antimicrobial class combinations presented a negative correlation between years and amount of antimicrobial consumed (in $\mathrm{mg} / \mathrm{BM}$ ), as shown in Table 3.
Throughout this period, Denmark and Switzerland implemented several measures that contributed to the observed reduction. In Denmark, the introduction of the "Yellow Card" system in 2010 induced a remarkable drop in the consumption of antimicrobials in pigs in 2010 and $2011(28,30)$, as shown in Figure 2. The "Yellow card" is a benchmarking system for antimicrobial consumption at the farm level. It was first implemented in the pig production sector and expanded to the cattle production sector in 2011. Initially, permit limits were set at twice the average of the antimicrobial consumption in a given age group. Farmers using more than twice the average are subjected to restrictions 
TABLE 2 | Antimicrobial consumption (in milligrams per kilogram of biomass) of different antimicrobial classes for pigs in Denmark and Switzerland (2007-2013).

\begin{tabular}{|c|c|c|c|c|c|c|c|c|c|}
\hline $\begin{array}{l}\text { Antimicrobial } \\
\text { class }\end{array}$ & Country & 2007 & 2008 & 2009 & 2010 & 2011 & 2012 & 2013 & $\begin{array}{c}\text { Average } \\
\text { percentage of } \\
\text { consumption per } \\
\text { country }\end{array}$ \\
\hline \multirow[t]{3}{*}{ Aminoglycosides } & Denmark & 3.5 & 2.5 & 2.8 & 2.7 & 2.4 & 2.6 & 2.6 & 5.3 \\
\hline & Switzerland & 3.5 & 3.6 & 3.5 & 3.1 & 3.2 & 3.0 & 3.0 & 3.5 \\
\hline & & {$[0.7-7.6]$} & {$[0.6-7.4]$} & {$[0.6-7.4]$} & {$[0.6-6.4]$} & {$[0.6-6.7]$} & {$[0.5-6.4]$} & {$[0.5-6.5]$} & {$[0.6-7.4]$} \\
\hline \multirow{3}{*}{$\begin{array}{l}\text { Cephalosporins } \\
\text { and } \\
\text { fluoroquinolones }\end{array}$} & Denmark & 0.1 & 0.1 & 0.1 & 0.0 & 0.0 & 0.0 & 0.0 & 0.1 \\
\hline & Switzerland & 0.4 & 0.4 & 0.4 & 0.4 & 0.4 & 0.4 & 0.4 & 0.4 \\
\hline & & {$[0.1-0.9]$} & {$[0.1-1.0]$} & {$[0.1-1.0]$} & {$[0.1-0.9]$} & {$[0.1-0.9]$} & {$[0.1-0.8]$} & {$[0.1-1.0]$} & {$[0.1-1.0]$} \\
\hline \multirow[t]{3}{*}{ Macrolides } & Denmark & 6.5 & 6.2 & 7.4 & 7.0 & 5.4 & 6.2 & 6.3 & 12.5 \\
\hline & Switzerland & 7.0 & 7.8 & 7.1 & 6.5 & 5.8 & 5.9 & 5.5 & 7.0 \\
\hline & & {$[2.1-13.4]$} & {$[2.3-14.8]$} & {$[2.1-13.8]$} & {$[1.8-12.7]$} & {$[1.5-11.3]$} & {$[1.8-11.2]$} & {$[1.6-10.9]$} & {$[2.0-13.5]$} \\
\hline \multirow[t]{3}{*}{ Penicillins } & Denmark & 13.4 & 13.1 & 14.7 & 14.7 & 12.8 & 12.9 & 13.7 & 26.6 \\
\hline & Switzerland & 9.4 & 10.4 & 10.4 & 9.8 & 10.2 & 9.5 & 10.1 & 10.7 \\
\hline & & {$[2.4-21.1]$} & {$[2.6-23.4]$} & [3.0-22.6] & {$[1.9-23.1]$} & {$[2.0-23.5]$} & {$[1.4-22.9]$} & {$[2.0-23.9]$} & [2.3-24.6] \\
\hline \multirow{3}{*}{$\begin{array}{l}\text { Sulfonamides/ } \\
\text { trimethoprim }\end{array}$} & Denmark & 3.9 & 4.1 & 5.0 & 4.8 & 3.9 & 4.2 & 5.0 & 8.7 \\
\hline & Switzerland & 41.1 & 44.5 & 41.1 & 36.9 & 31.6 & 31.7 & 28.4 & 39.1 \\
\hline & & [14.8-84.7] & [16.6-89.6] & [15.4-82.6] & [12.6-74.3] & {$[9.5-67.2]$} & [12.0-64.9] & [10.7-58.2] & [14.0-79.9] \\
\hline \multirow[t]{3}{*}{ Tetracyclines } & Denmark & 18.9 & 18.6 & 19.4 & 17.4 & 14.2 & 15.9 & 16.8 & 33.8 \\
\hline & Switzerland & 40.5 & 38.2 & 33.9 & 29.7 & 26.4 & 22.5 & 23.7 & 32.9 \\
\hline & & [31.3-56.3] & [27.4-57.0] & {$[24.1-51.4]$} & [20.7-45.6] & [17.6-42.0] & [14.1-36.8] & [15.6-37.6] & [23.1-50.1] \\
\hline \multirow[t]{3}{*}{ Others } & Denmark & 5.7 & 7.8 & 7.7 & 7.5 & 5.7 & 5.7 & 6.6 & 13.0 \\
\hline & Switzerland & 6.8 & 6.0 & 5.9 & 5.6 & 6.9 & 5.0 & 4.7 & 6.3 \\
\hline & & [5.5-8.6] & {$[4.4-7.9]$} & {$[4.5-7.7]$} & {$[4.5-7.2]$} & {$[5.4-8.6]$} & [3.9-6.3] & {$[3.5-5.8]$} & {$[4.9-8.0]$} \\
\hline \multirow[t]{3}{*}{ Total } & Denmark & 52.0 & 52.4 & 57.0 & 54.2 & 44.4 & 47.5 & 51.0 & 100.0 \\
\hline & Switzerland & 108.6 & 110.9 & 102.4 & 92.1 & 84.4 & 78.0 & 75.9 & 100.0 \\
\hline & & [56.7-192.3] & [54.0-201.3] & [49.8-186.4] & [42.1-170.2] & [36.6-160.3] & [33.7-149.4] & [34.0-143.8] & \\
\hline
\end{tabular}

For Swiss estimates, the 95\% credibility intervals are presented in square brackets. "Others" include amphenicols, quinolone, lincosamides (with or not combination with spectinomycin), pleuromutilins, and polypeptide antibiotics. Due to confidentiality reasons, fluoroquinolones and cephalosporins have been grouped together.

imposed by the Danish Veterinary and Food Administration (28). Despite the subsequent increase in antimicrobial consumption in pigs from 2011 to 2013, it should be noted that a $10.0 \%$ decrease in the tonnage of prescribed antimicrobials for pigs has been observed from 2013 to 2015 (31). This followed the implementation of lower permit limits by the Danish Food and Veterinary Administration in September 2012 and again in February 2014 (32). In Switzerland, multiple factors might have contributed to the observed reduction. First, several educational initiatives presumably increased awareness among farmers and veterinarians regarding the risks associated with antimicrobial usage and the associated development of antimicrobial resistance. These educational programmes started after the introduction of the Tierarzneimittelverordnung (Ordinance on veterinary drugs) in 2004 (33) and have been gradually implemented since then. Since 2015, these various programs are coordinated within a national strategy to reduce selection and development of bacterial resistances [StAR program (34)]. Additionally, the commercialization of vaccines (against Lawsonia intracellularis in 2006 and Porcine Circovirus-2 in 2009) might have also played a role in the pig sector. In cattle, more specifically, the Bovine Viral Diarrhea eradication program initiated in 2008 (35) probably also contributed to the observed trend, as animals became less susceptible to secondary bacterial infections (36).
When comparing 2013 to 2007, the total reduction in the calculated antimicrobial consumption in Switzerland was $30.1 \%$ for pigs and $24.5 \%$ for cattle, while Denmark-from an already lower level-achieved a total reduction of $1.9 \%$ in pigs and $6.9 \%$ in cattle. We hypothesize that these differences are partly related to the fact the Switzerland had a much higher consumption than Denmark in the beginning of the study period. It is more difficult for a system closer to the lower limit of antimicrobial usage, such as the Danish one, to achieve large reductions, than for a system with higher antimicrobial consumption and multiple opportunities for improvement. This was already demonstrated in The Netherlands where, through a series of interventions, a reduction of 56\% between 2007 and 2012 (37) was achieved. But, the overall antimicrobial consumption in The Netherlands was the highest (179 mg/PCU) among the nine countries (Switzerland and Denmark being among those) included in the first ESVAC report (1).

The results were corrected for the population size and species; therefore, differences related to these factors are not expected to have an effect on the results. Differences in animal health status could provide an obvious explanation for a higher need for antimicrobials. As Switzerland is currently free of porcine respiratory and reproductive syndrome (PRRS) and has nearly eradicated enzootic pneumonia and porcine pleuropneumonia (38), but 


\section{A \\ Relative consumption of antimicrobial classes for pigs in Denmark}

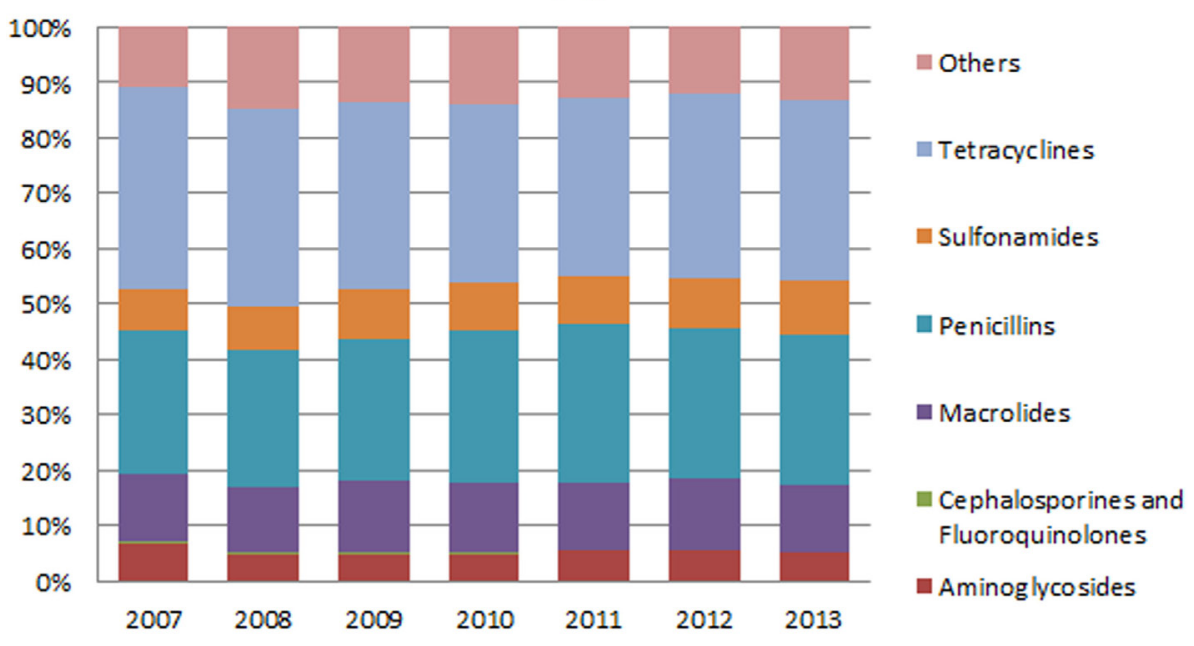

\section{B Relative consumption of antimicrobial classes for pigs in Switzerland}

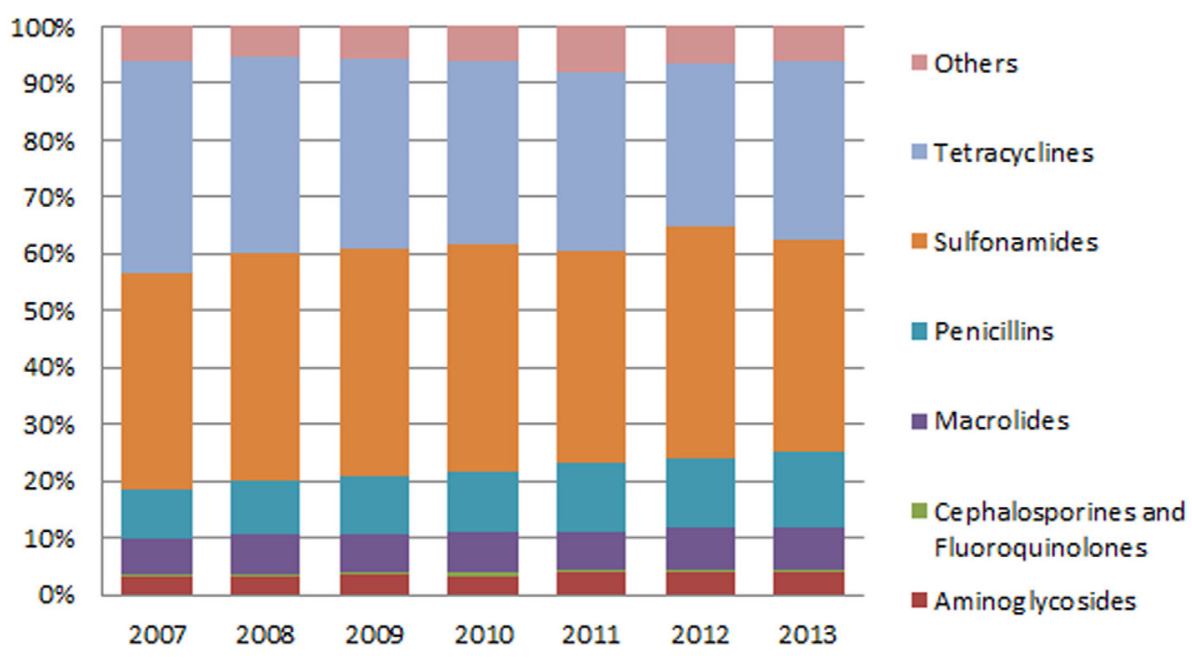

FIGURE 4 | Comparison of the relative consumption of different antimicrobial classes between Denmark (A) and Switzerland (B) for use in pigs "Others" include amphenicols, quinolone, lincosamide (with or not combination with spectinomycin), pleuromutilins, and polypeptide antibiotics. Due to confidentiality reasons, fluoroquinolones and cephalosporins have been grouped together.

still uses more antimicrobials compared to Denmark, where these diseases are still present $(39,40)$, additional factors must be sought to explain the differences in the pig sector. One explanation may be the Danish specific pathogen-free (SPF) system, which was initiated in 1971 (41). More than $70 \%$ of sow herds are part of the SPF system, and a substantial part of the finishing herds are either part of the SPF system or comply with the biosecurity rules set by the SPF system. Herds in the system are monitored for absence of the most important swine infections such as PRRS, Mycoplasma hyopneumoniae, Pasteurella multocida, Brachyspira hyodysenteriae, Actinobacillus pleuropneumoniae, lice, and scabies. In the case where a herd is infected with any of these pathogens, its health status is declared in the SPF system. This declaration is made public, allowing producers to purchase replacement gilts from herds having the same status as his own.

For cattle, the disease status is similar between the countries, which, again does not explain the observed differences in antimicrobial consumption. Nevertheless, interventions implemented in Denmark might elucidate some differences. Intramammary treatments account for a large proportion of antimicrobial consumption in dairy cattle (42). In Denmark, dry-cow treatment is not allowed without a bacteriological analysis of a milk sample 35 days before administering the injectors (43). 
TABLE 3 | Correlation coefficients between years (2007-2013) and antimicrobial consumption for each combination of species/country/ antimicrobial class.

\begin{tabular}{llrr}
\hline Country & Antimicrobial class & \multicolumn{2}{c}{$\begin{array}{c}\text { Correlation } \\
\text { coefficient }\end{array}$} \\
\cline { 3 - 4 } & & Cattle & Pigs \\
\hline Denmark & Aminoglycosides & -0.91 & -0.61 \\
Switzerland & Aminoglycosides & -0.94 & -0.90 \\
Denmark & Cephalosporins and fluoroquinolones & 0.63 & -0.87 \\
Switzerland & Cephalosporins and fluoroquinolones & 0.40 & $\mathrm{NA}$ \\
Denmark & Macrolides & -0.88 & -0.31 \\
Switzerland & Macrolides & -0.97 & -0.89 \\
Denmark & Penicillins & 0.41 & -0.13 \\
Switzerland & Penicillins & -0.07 & 0.02 \\
Denmark & Sulfonamides/trimethoprim & -0.90 & 0.37 \\
Switzerland & Sulfonamides/trimethoprim & -1.00 & -0.93 \\
Denmark & Tetracyclines & -0.62 & -0.71 \\
Switzerland & Tetracyclines & -0.83 & -0.98 \\
Denmark & Others & 0.94 & -0.27 \\
Switzerland & Others & NA & -0.66 \\
Denmark & Total antimicrobial consumption & -0.29 & -0.47 \\
Switzerland & Total antimicrobial consumption & -0.98 & -0.97 \\
\hline "Others"include amphenicols, quinolone, incosamides (with & & & \\
\hline
\end{tabular}

"Others" include amphenicols, quinolone, lincosamides (with or not combination with spectinomycin), pleuromutilins, and polypeptide antibiotics. Due to confidentiality reasons, fluoroquinolones and cephalosporins have been grouped together.

The differences between countries in the use of other substances to substitute antimicrobials, such as zinc oxide, could partly explain some of the observed differences. Other aspects that may play a role, both in the overall antimicrobial consumption, as well as in the specific substances used, are farming conditions (44-46). Postma et al. (44) concluded that a better external biosecurity in pig farms was related to a lower usage of antimicrobials. Biosecurity is not a high priority for Swiss swine farms (47). Completely closed farms are the minority, and nearly half of all farmers practice all-in all-out production $(9,47)$. On the contrary, biosecurity in Denmark is of high priority and regular visits to inspect external biosecurity are a prerequisite for farms wishing to be part of the SPF system. In addition, resistance patterns of animal pathogens may also be an underlying factor influencing treatment choices (25). However, the resistance situation in both countries is favorable when compared with other European countries $(48,49)$.

In summary, all the previously mentioned factors can potentially explain some of the observed differences between the two countries. An interesting feature that has not been thoroughly investigated relates to the influence of education and awareness on the prescription patterns of practitioners, as well as on the treatment practices of farmers. With regards to the relative consumption of antimicrobial classes, an important factor that could shed some light on the differences observed between the countries is the existence of treatment guidelines in Denmark. In Switzerland, guidelines for specific species and indications are still under development and will be published in 2017. In Denmark, these recommendations were first issued in 1996 and have been updated throughout time (50). Focus was set on prudent use as well as on the correct choice of antimicrobials for specific treatments. This might contribute to some of the observed preference, such as the use of penicillins. Another example is the Danish Order (DK) 785/2010, which recommends the use of penicillins for the treatment of mastitis (18). Any mastitis treatment with antimicrobials other than penicillins requires the previous bacterial and susceptibility testing of a milk sample. This might partially explain the discrepancies observed between the countries on the relative proportion of antimicrobial classes administered to cattle (43). For pigs, requirements from certain markets, such as the American, regarding sulfonamides' residues might partly explain the lower relative consumption of this class in Denmark. An additional point to consider relates to differences in product availability $(51,52)$. The most notable examples are the limitations in the prescription of fluoroquinolones (27) and the ban on third/ fourth generation cephalosporins put in place by the Danish pig industry (29).

Given the descriptive nature of this study, we can only emphasize the need to further investigate these observations and hypothesize on potential contributing factors. This is of relevance given the need to further reduce the consumption of antimicrobials in livestock species and preserve the efficacy of these substances for human use, without jeopardizing animal health, productivity, and animal welfare.

\section{Study Limitations}

Our study has some limitations that need to be addressed. Antimicrobial consumption estimates from Switzerland were extrapolated from sales data using information from a previous field study (12). On the other hand, Danish consumption values presented on DANMAP reports were directly taken from the VetStat database. Therefore, the data on Danish antimicrobial consumption are considered to be more accurate, since they were based on prescription data (closer to the actual usage than sales data) with a national coverage. The fact that Swiss estimates rely on a field study might have introduced some bias. It should also be noted that uncertainty around some of the Swiss estimates was large. This relates to the minimum and maximum values used in the Pert distributions. These values were calculated based on sales data (from the Swiss Federal Food Safety and Veterinary Office) as the minimum and maximum amounts of each antimicrobial class that could have been sold for consumption in a given species. For antimicrobial classes where the interval between the minimum and the maximum was larger, uncertainty was also increased. Another study limitation relates to the fact that antimicrobial consumption by dairy cattle and beef cattle were put together, for both Denmark and Switzerland. These production systems are associated with different health issues, which might lead to the use of dissimilar antimicrobial substances. Furthermore, the proportion of dairy and non-dairy herds varies considerably between the two countries: $18 \%$ dairy versus $82 \%$ non-dairy in Denmark (22) and 57\% dairy versus $43 \%$ non-dairy in Switzerland (23). Nevertheless, it should be noted that the average number of animals might differ between countries and production systems. Therefore, the proportion of animals at risk of being treated (dairy versus non-dairy) with antimicrobials can be different than the percentages indicated above. 
Animal age categories and types of production were not taken into account in our analysis as the Swiss antimicrobial consumption estimates were not detailed enough. However, it is known that these parameters could also influence antimicrobial consumption $(25,53)$ and should, if possible, be considered in future comparative studies.

\section{Final Remarks}

In conclusion, we found substantial variations between Denmark and Switzerland on the relative consumption of different antimicrobial classes in cattle and pigs. Several factors other than animal demographics might contribute to the differences observed on overall antimicrobial sales, as well as the relative consumption of antimicrobial classes, across Europe. These factors should be further investigated to better understand drivers of antimicrobial usage and prioritize more efficient mitigation strategies.

\section{REFERENCES}

1. European Medicines Agency, European Surveillance of Veterinary Antimicrobial Consumption. Trends in the Sales of Veterinary Antimicrobial Agents in Nine European Countries (2005-2009). (2011). Available from: http://www.ema.europa.eu/docs/en_GB/document_library/Report/2011/09/ WC500112309.pdf

2. European Medicines Agency, European Surveillance of Veterinary Antimicrobial Consumption. Sales of Veterinary Antimicrobial Agents in 19 EU/EEA Countries in 2010: Second ESVAC Report. (2012). Available from: http://www.ema.europa.eu/docs/en_GB/document_library/Report/2012/10/ WC500133532.pdf

3. European Medicines Agency, European Surveillance of Veterinary Antimicrobial Consumption. Sales of Veterinary Antimicrobial Agents in 25 EU/EEA Countries in 2011: Third ESVAC Report. (2013). Available from: http://www.ema.europa.eu/docs/en_GB/document_library/Report/2013/10/ WC500152311.pdf

4. European Medicines Agency, European Surveillance of Veterinary Antimicrobial Consumption. Sales of Veterinary Antimicrobial Agents in 26 EU/EEA Countries in 2012: Fourth ESVAC Report. (2014). Available from: http://www.ema.europa.eu/docs/en_GB/document_library/Report/2014/10/ WC500175671.pdf

5. European Medicines Agency, European Surveillance of Veterinary Antimicrobial Consumption. Sales of Veterinary Antimicrobial Agents in 25 EU/EEA Countries in Fifth ESVAC Report. (2013). Available from: http:// www.ema.europa.eu/docs/en_GB/document_library/Report/2015/10/ WC500195687.pdf

6. Grave K, Torren-Edo J, Mackay D. Comparison of the sales of veterinary antibacterial agents between 10 European countries. J Antimicrob Chemother (2010) 65:2037-40. doi:10.1093/jac/dkq247

7. Speksnijder DC, Jaarsma ADC, van der Gugten AC, Verheij TJM, Wagenaar JA. Determinants associated with veterinary antimicrobial prescribing in farm animals in the Netherlands: a qualitative study. Zoonoses Public Health (2015) 62:39-51. doi:10.1111/zph.12168

8. Backhans A, Sjölund M, Lindberg A, Emanuelson U. Antimicrobial use in Swedish farrow-to-finish pig herds is related to farmer characteristics. Porcine Health Manag (2016) 2:1-7. doi:10.1186/s40813-0160035-0

9. Visschers VHM, Iten DM, Riklin A, Hartmann S, Sidler X, Siegrist M. Swiss pig farmers' perception and usage of antibiotics during the fattening period. Livest Sci (2014) 162:223-32. doi:10.1016/j.livsci.2014.02.002

10. Van Boeckel TP, Brower C, Gilbert M, Grenfell BT, Levin SA, Robinson TP, et al. Global trends in antimicrobial use in food animals. Proc Natl Acad Sci U S A (2015) 112(18):5649-54. doi:10.1073/pnas.1503141112

11. Swissmedic. Information für Fachpersonen Antibiotika für die Veterinärmedizin: Vertriebszahlen der Jahre 2004 bis 2006 [Information for professionals. Antibiotics in veterinary medicine: Sales data for the years 2004

\section{AUTHOR CONTRIBUTIONS}

LPC analyzed the data, interpreted the results, and wrote the manuscript. LN and LA provided valuable expertise on the topic, especially on the interpretation of Danish data. CM and GS-R also provided valuable expertise on the topic, with special emphasis on the interpretation of Swiss data. IM was the main supervisor of the $\mathrm{PhD}$ student and assisted the first author (LPC) in all steps of the study. All the authors actively contributed to the conception of the project, have read, and approved the manuscript.

\section{FUNDING}

This study is part of the $\mathrm{PhD}$ project of LPC, which is funded by the Swiss Federal Food Safety and Veterinary Office-project number 1.12.21.

to 2006]. (2007). Available from: https://www.swissmedic.ch/marktueberwachung/00135/00136/00181/index.html?lang=en

12. Carmo LP, Schuepbach-Regula G, Muentener C, Chevance A, Moulin G, Magouras I. Approaches for quantifying antimicrobial consumption per animal species based on national sales data: a Swiss example 2006 to 2013. Euro Surveill (2017) 22(6). doi:10.2807/1560-7917.ES.2017.22.6. 30458

13. Stege H, Bager F, Jacobsen E, Thougaard A. VETSTAT - the Danish system for surveillance of the veterinary use of drugs for production animals. Prev Vet Med (2003) 57:105-15. doi:10.1016/S0167-5877(02)00233-7

14. Regula G, Torriani K, Gassner B, Stucki F, Müntener CR. Prescription patterns of antimicrobials in veterinary practices in Switzerland. J Antimicrob Chemother (2009) 63:805-11. doi:10.1093/jac/dkp009

15. DANMAP. DANMAP 2007 - Use of Antimicrobial Agents and Occurrence of Antimicrobial Resistance in Bacteria from Food Animals, Foods and Humans in Denmark. (2008). Available from: http://www.danmap.org/ /media/ Projekt\%20sites/Danmap/DANMAP\%20reports/Danmap_2007.ashx

16. DANMAP. DANMAP 2008 - Use of Antimicrobial Agents and Occurrence of Antimicrobial Resistance in Bacteria from Food Animals, Foods and Humans in Denmark. (2009). Available from: http://www.danmap.org/ /media/ Projekt\%20sites/Danmap/DANMAP\%20reports/Danmap_2008.ashx

17. DANMAP. DANMAP 2009 - Use of Antimicrobial Agents and Occurrence of Antimicrobial Resistance in Bacteria from Food Animals, Foods and Humans in Denmark. (2010). Available from: http://www.danmap.org/ /media/ Projekt\%20sites/Danmap/DANMAP\%20reports/Danmap_2009.ashx

18. DANMAP. DANMAP 2010 - Use of Antimicrobial Agents and Occurrence of Antimicrobial Resistance in Bacteria from Food Animals, Foods and Humans in Denmark. (2011). Available from: http://www.danmap.org/ /media/ Projekt\%20sites/Danmap/DANMAP\%20reports/Danmap_2010.ashx

19. DANMAP. DANMAP 2011 - Use of Antimicrobial Agents and Occurrence of Antimicrobial Resistance in Bacteria from Food Animals, Food and Humans in Denmark. (2012). Available from: http://www.danmap.org/ /media/ Projekt\%20sites/Danmap/DANMAP\%20reports/Danmap_2011.ashx

20. DANMAP. DANMAP 2012 - Use of Antimicrobial Agents and Occurrence of Antimicrobial Resistance in Bacteria from Food Animals, Food and Humans in Denmark. (2013). Available from: http://www.danmap.org/ /media/ Projekt\%20sites/Danmap/DANMAP\%20reports/DANMAP\%202012/ Danmap_2012.ashx

21. DANMAP. DANMAP 2013 - Use of Antimicrobial Agents and Occurrence of Antimicrobial Resistance in Bacteria from Food Animals, Food and Humans in Denmark. (2014). Available from: http://www.danmap.org/ /media/ Projekt\%20sites/Danmap/DANMAP\%20reports/DANMAP\%202013/ DANMAP\%202013.ashx

22. Danish Agricultural and Food Council SEGES. (2016). Available from: http:// www.kvaegvet.dk/Dublin/AASduHist.html

23. Swiss Federal Statistical Office. Landwirtschaft und Ernährung Taschenstatistik 2016 [Food and Agriculture - Pocket Statistics 2016]. Neuchâtel (2016). 
Available from: https://www.bfs.admin.ch/bfs/en/home/statistics/agriculture-forestry/food.gnpdetail.2016-0214.html

24. Microsoft Corporation. Microsoft Exce ${ }^{\mathrm{TM}}$. Redmont, Washington: Microsoft Corporation (2010).

25. Sjölund M, Postma M, Collineau L, Lösken S, Backhans A, Belloc C, et al. Quantitative and qualitative antimicrobial usage patterns in farrow-to-finish pig herds in Belgium, France, Germany and Sweden. Prev Vet Med (2016) 130:41-50. doi:10.1016/j.prevetmed.2016.06.003

26. Bondt N, Jensen VF, Puister-Jansen LF, van Geijlswijk IM. Comparing antimicrobial exposure based on sales data. Prev Vet Med (2013) 108:10-20. doi:10.1016/j.prevetmed.2012.07.009

27. Aarestrup FM, Jensen VF, Emborg H-D, Jacobsen E, Wegener HC. Changes in the use of antimicrobials and the effects on productivity of swine farms in Denmark. Am J Vet Res (2010) 71(7):726-33. doi:10.2460/ajvr.71.7.726

28. Alban L, Dahl J, Andreasen M, Petersen JV, Sandberg M. Possible impact of the "yellow card" antimicrobial scheme on meat inspection lesions in Danish finisher pigs. Prev Vet Med (2013) 108:334-41. doi:10.1016/ j.prevetmed.2012.11.010

29. Agersø Y, Aarestrup FM. Voluntary ban on cephalosporin use in Danish pig production has effectively reduced extended-spectrum cephalosporinase-producing Escherichia coli in slaughter pigs. J Antimicrob Chemother (2013) 68:569-72. doi:10.1093/jac/dks427

30. Jensen VF, de Knegt LV, Andersen VD, Wingstrand A. Temporal relationship between decrease in antimicrobial prescription for Danish pigs and the "yellow card" legal intervention directed at reduction of antimicrobial use. Prev Vet Med (2014) 117:554-64. doi:10.1016/j.prevetmed.2014.08.006

31. DANMAP. DANMAP 2015 - Use of Antimicrobial Agents and Occurrence of Antimicrobial Resistance in Bacteria from Food Animals, Food and Humans in Denmark. (2016). Available from: http://www.danmap.org/ /media/ Projekt\%20sites/Danmap/DANMAP\%20reports/DANMAP\%20\%202015/ DANMAP\%202015.ashx

32. Fødevarestyrelsen [Danish Food and Veterinary Administration]. Gult Kort [Yellow Card]. (2017). Available from: https://www.foedevarestyrelsen.dk/ Leksikon/Sider/Gult-kort.aspx

33. The Swiss Federal Council. Verordnung über die Tierarzneimittel (Tierarzneimittelverordnung, TAMV) [Animal Drugs Ordinance]. (2004). Available from: https://www.admin.ch/opc/de/classified-compilation/ 20030705/index.html

34. Swiss Federal Food Safety and Veterinary Office. StAR Programme. (2016). Available from: https://www.blv.admin.ch/blv/de/home/das-blv/strategien/ nationale-strategie-antibiotikaresistenzen.html

35. Presi P, Heim D. BVD eradication in Switzerland - a new approach. Vet Microbiol (2010) 142:137-42. doi:10.1016/j.vetmic.2009.09.054

36. Brodersen BW. Bovine viral diarrhea virus infections: manifestations of infection and recent advances in understanding pathogenesis and control. Vet Pathol (2014) 51:453-64. doi:10.1177/0300985813520250

37. Speksnijder DC, Mevius DJ, Bruschke CJM, Wagenaar JA. Reduction of veterinary antimicrobial use in the Netherlands. The Dutch success model. Zoonoses Public Health (2015) 62:79-87. doi:10.1111/zph.12167

38. Swiss Federal Food Safety and Veterinary Office. (2016). Available from: https://www.infosm.blv.admin.ch/public/awzeit/index

39. Danish Veterinary and Food Administration. Animal Health in Denmark 2014. Glostrup (2015). Available from: https://www.foedevarestyrelsen. $\mathrm{dk} /$ Publikationer/Alle\%20publikationer/15593\%20Animal\%20health\%20 2014_WEB.pdf

40. Temtem C, Kruse AB, Nielsen LR, Pedersen KS, Alban L. Comparison of the antimicrobial consumption in weaning pigs in Danish sow herds with different vaccine purchase patterns during 2013. Porcine Health Manag (2016) 2:1-11. doi:10.1186/s40813-016-0042-1
41. Danish Agriculture and Food Council. Danish SPF-System. (2016). Available from: http://spfsus.dk/en

42. De Briyne N, Atkinson J, Pokludová L, Borriello SP. Antibiotics used most commonly to treat animals in Europe. Vet Rec (2014) 175:325. doi:10.1136/ vr.102462

43. BEK nr.1362 of 30/11/2015. (2015). Available from: https://www.retsinformation.dk/forms/R0710.aspx?id=175789

44. Postma M, Backhans A, Collineau L, Loesken S, Sjolund M, Belloc C, et al. The biosecurity status and its associations with production and management characteristics in farrow-to-finish pig herds. Animal (2016) 10(3):478-89. doi:10.1017/S1751731115002487

45. Laanen M, Persoons D, Ribbens S, de Jong E, Callens B, Strubbe M, et al. Relationship between biosecurity and production/antimicrobial treatment characteristics in pig herds. Vet $J$ (2013) 198:508-12. doi:10.1016/ j.tvjl.2013.08.029

46. Fertner M, Sanchez J, Boklund A, Stryhn H, Dupont N, Toft N. Persistent spatial clusters of prescribed antimicrobials among Danish pig farms - a register-based study. PLoS One (2015) 10:e0136834. doi:10.1371/journal. pone. 0136834

47. Arnold C, Schüpbach-Regula G, Hirsiger P, Malik J, Scheer P, Sidler X, et al. Risk factors for oral antimicrobial consumption in Swiss fattening pig farms - a case-control study. Porcine Health Manag (2016) 2:5. doi:10.1186/ s40813-016-0024-3

48. European Food Safety Authority, European Centre for Disease Prevention and Control. The European Union Summary Report on antimicrobial resistance in antimicrobial resistance in zoonotic and indicator bacteria from humans, animals and food in the European Union in 2014. EFSA J (2016) 14:207. doi:10.2903/j.efsa.2016.4380

49. Federal Food Safety and Veterinary Office. ARCH-VET 2014: Bericht über den Vertrieb von Antibiotika in der Veterinärmedizin und das Antibiotikaresistenzmonitoring bei Nutztieren in der Schweiz [ARCH-VET 2014: Report on sales of antibiotics for veterinary use and antibiotic resistance monitoring in livestock in Switzerland]. (2015):1-80. Available from: https://www.blv.admin.ch/blv/de/home/tiere/publikationen-und-forschung/ statistiken-berichte-tiere.html

50. DANMAP. DANMAP 2014 - Use of Antimicrobial Agents and Occurrence of Antimicrobial Resistance in Bacteria from Food Animals, Food and Humans in Denmark. (2015). Available from: http://www.danmap.org/ /media/ Projekt\%20sites/Danmap/DANMAP\%20reports/DANMAP\%202014/ Danmap_2014.ashx

51. Institut für Veterinärpharmakologie und -toxikologie. Veterinary Swiss Drug Compendium. (2015). Available from: http://www.vetpharm.uzh.ch/perldocs/ index_i.htm

52. Medicin Til Dyr. (2016). Available from: http://www.medicintildyr.dk/

53. Callens B, Persoons D, Maes D, Laanen M, Postma M, Boyen F, et al. Prophylactic and metaphylactic antimicrobial use in Belgian fattening pig herds. Prev Vet Med (2012) 106:53-62. doi:10.1016/j.prevetmed.2012.03.001

Conflict of Interest Statement: The authors declare that the research was conducted in the absence of any commercial or financial relationships that could be construed as a potential conflict of interest.

Copyright (c) 2017 Carmo, Nielsen, Alban, Müntener, Schüpbach-Regula and Magouras. This is an open-access article distributed under the terms of the Creative Commons Attribution License (CC BY). The use, distribution or reproduction in other forums is permitted, provided the original author(s) or licensor are credited and that the original publication in this journal is cited, in accordance with accepted academic practice. No use, distribution or reproduction is permitted which does not comply with these terms. 